\title{
Oncological and functional outcomes of transanal total mesorectal excision in a teaching hospital in the Netherlands
}

Joost A.G. van der Heijden, Kelly G.H. van de Pas, Frank J.C. van den Broek, Francois M.H. van Dielen, Gerrit D. Slooter, Adriana J.G. Maaskant-Braat

Department of Surgery, Máxima Medical Centre, Veldhoven, the Netherlands

Purpose: Transanal total mesorectal excision (TaTME) was developed to overcome surgical difficulties experienced in distal pelvic dissection. Concerns have been raised about potential worse postoperative functional outcomes after TaTME. Also, the oncological safety was questioned. This study aimed to describe the functional, surgical, oncological outcomes and quality of life (QoL) after TaTME.

Methods: All consecutive TaTME cases for rectal cancer without disseminated disease between December 2016 and April 2019 were included. The Wexner incontinence score, low anterior resection syndrome (LARS) score, fecal incontinencerelated QoL, and the European Organisation for Research and Treatment of Cancer Quality of Life Questionnaire-core questionnaire and 29-item module (EORTC QLQ-C30/CR29) were collected. Kaplan-Meier analysis was used to calculate local recurrence-free survival.

Results: Thirty patients were eligible for analysis of which 23 received questionnaires. Response rate was $74 \%$. After a median follow-up of respectively 20.0 and 23.0 months for functional and oncological outcomes, the median (interquartile range) of Wexner incontinence and LARS scores were 9.0 (7.0-12.0) and 33.1 (25.0-39.0). Major LARS was present in 73.3\%. Fecal incontinence, general and colorectal-specific QoL subdomains that are associated with poor bowel function scored in line with previously reported data. The 2-year actuarial cumulative local recurrence rate was 3.7\% (95\% confidence interval, $2.4 \%-5.0 \%)$.

Conclusion: TaTME may lead to significant functional impairments. Patients should receive preoperative counseling on this topic and be fully aware of the potential consequences of their treatment. Oncological data were in line with other short- to moderate-term data and did not show alarming results.

Keywords: Colorectal surgery; Patient reported outcome measures; Functional status; Quality of life

\section{INTRODUCTION}

Total mesorectal excision (TME) is the most effective surgical treat-

Received: Sep 1, 2020 - Revised: Oct 2, 2020 - Accepted: Oct 6, 2020

Correspondence to: Adriana J.G. Maaskant-Braat, M.D.

Department of Surgical Oncology, Máxima Medical Centre,

P.0. 7777, 5500 MB Veldhoven, the Netherlands

Tel: +31-408888000

E-mail: sabrina.maaskant@mmc.n

ORCID: https://orcid.org/0000-0002-9827-6915

(c) 2022 The Korean Society of Coloproctology

This is an open-access article distributed under the terms of the Creative Commons Attribution NonCommercial License (https://creativecommons.org/licenses/by-nc/4.0) which permits unrestricted non-

commercial use, distribution, and reproduction in any medium, provided the original work is properly cited. ment for rectal cancer in terms of local recurrence (LR) rates and survival outcomes [1] but is also associated with serious comorbidities that have the potential to affect functional performance and quality of life (QoL) of patients that underwent TME [2-4].

Advances in surgical insights have led to the development of new surgical techniques. One of them originates from 2009 [5] and involves performing TME by transanal minimally invasive surgery. This procedure is called transanal TME (TaTME) and has been developed to overcome surgical difficulties experienced during distal pelvic dissection by improving visualization of surgical planes and margins [6]. In the introduction phase of this technique, an alarming short-term LR rate of $8 \%$ to $10 \%$ was reported by Larsen et al. [7], but recently more data on short to moderate- 
term oncological data became available that suggest that TaTME is as safe as laparoscopic TME for low rectal cancer [8-10] if performed at high-volume centers that included a proctoring program in the introduction phase of the technique.

An important feature of TaTME is that it allows for the construction of a low anastomosis in patients who otherwise would be treated with abdominoperineal resection. It is this factor, in combination with potential sphincter damage due to the positioning of the transanal platform in the anal canal [11-13], that raised concerns regarding functional outcomes after TaTME.

A systematic review of the literature suggested no significant differences in functional outcomes after TaTME compared with laparoscopic TME surgery [14, 15]. However, since fecal incontinence and bowel dysfunction have a major impact on the physical, psychological, social, and emotional functioning of the patient $[3,16-$ $18]$, it is important to further explore its presence and impact in patients after TaTME.

Therefore, this study aimed to report the surgical, functional, and QoL-related outcomes for the first set of patients that were treated with TaTME as a new technique for distal rectal cancer in a teaching hospital in the Netherlands.

\section{METHODS}

\section{Study design}

A retrospective institutional cohort study was conducted in a single-center teaching hospital in the Netherlands. Consecutive patients that underwent TaTME for rectal cancer were identified through electronic patient registries and invited to fill out questionnaires. Inclusion criteria were a history of TaTME for rectal cancer and age above 18 years. All surgical and oncology-related outcomes were collected from patient files. Exclusion criteria for questionnaire participation were no informed consent, disseminated disease at presentation, or incapability to fill out the questionnaires due to linguistic barriers or severe cognitive/physical impairments. The decision to perform TaTME was dependent on (low) tumor height in combination with the pelvic anatomy of the patient. If both features hampered a regular low anterior resection, a transanal approach was chosen. All 4 surgeons performing TaTME participated in a proctorship program during the introduction of TaTME [19] of which 3 of them performed the majority of cases included in this study. A 2-team approach was used. The number of cases per surgeon ranged from 9 to 14 procedures with regard to the described cohort.

Since the timing of assessment is important for the interpretation of functional results, only patients were included for questionnaire participation who were at least 6 months with bowel continuity or at least 6 months with a stoma. Questionnaires and a reminder were sent between October 2019 and February 2020. Approval from the Ethical Committee of Máxima Medical Centre was obtained prior to the start of this study (No. N19.042) and all patients provided written informed consent.

\section{Outcomes of interest}

\section{Surgical and oncology-related outcomes}

Collected data included stoma construction rate, type of anastomosis, number of operating teams, conversion rate, reoperation within 30 days, length of hospital stays, LR rate, and incidence of metastasis during follow-up. Next to this, postoperative complications such as anastomotic leakage $(\mathrm{AL})$ rates were collected. An AL was defined as associated clinical symptoms and increased inflammatory markers with contrast extravasation on computed tomography scan and/or a defect visible during endoscopy [20]. The Dutch guidelines for routine follow-up were followed.

\section{Patient-reported outcome measures}

Patients with a stoma received the European Organisation for Research and Treatment of Cancer Quality of Life Questionnaire-core questionnaire and 29-item module (EORTC QLQ-C30/CR29), while patients with bowel continuity also received the low anterior resection syndrome (LARS) score, Wexner incontinence score, and Fecal Incontinence Quality of Life (FIQL).

LARS score: This score is validated for scoring bowel dysfunction after low anterior resection for colorectal cancer. Reference data are documented [21]. It covers the 5 most bothersome issues in terms of prevalence and impact of QoL, namely incontinence for flatus and liquid stool, frequency, clustering, and urgency. Scores range from 0 to 42, with subdivisions in 3 categories; no (0-20), minor (21-29), and major LARS (30-42).

Wexner incontinence scale: This questionnaire assesses the severity, type and frequency of fecal incontinence, and its impact on daily life. Scores range from 0 (continent) to 20 (highest severity of incontinence), with categories of asymptomatic (0), minor (1$4)$, moderate (5-8), and severe $(>8)$ incontinence. It has an important association with the FIQL score [22].

Fecal Incontinence Quality of Life: The FIQL score is a conditionspecific questionnaire on QoL and consists of 4 multi-item subscales; lifestyle, coping/behavior, depression/self-perception, and embarrassment. Scores range from 1 to 4 where 1 represents a low QoL and 4 represents a high QoL [23]. The FIQL questionnaire does not categorize scores into clinical groups.

European Organisation for Research and Treatment of Cancer Quality of Life Questionnaire: The modules CR29 and C30 version were used to measure colorectal cancer-specific and general QoL $[24,25]$. Scores range from 0 to 100; a higher score represents a higher ("better") level of functioning or a higher ("worse") level of symptoms. No categorization of scores is used, but EORTC QLQC30 reference population scores are available.

\section{Statistical analysis}

All categorical data were presented as percentages, where a mean with standard deviation (SD) or median with interquartile range (IQR) was presented for continuous data, depending on distribution of data. Where appropriate, 95\% confidence intervals (CI) were provided. For the EORTC QLQ, linear transformation of raw 
Table 1. Patient characteristics

\begin{tabular}{|c|c|c|}
\hline Variable & $\begin{array}{l}\text { TaTME total } \\
\text { group } \\
(n=30)\end{array}$ & $\begin{array}{l}\text { TaTME question- } \\
\text { naire completer } \\
\quad(n=17)\end{array}$ \\
\hline \multicolumn{3}{|l|}{ Demographic } \\
\hline Age (yr) & $65.5 \pm 9.0$ & $67.2 \pm 7.0$ \\
\hline Males & $24(80.0)$ & $12(70.6)$ \\
\hline Body mass index $\left(\mathrm{kg} / \mathrm{m}^{2}\right)$ & $25.6(23.5-27.8)$ & $25.6(23.3-28.9)$ \\
\hline \multicolumn{3}{|l|}{ ASA PS classification } \\
\hline I & $6(20.0)$ & $3(17.6)$ \\
\hline$\|$ & $21(70.0)$ & $12(70.6)$ \\
\hline III & $3(10.0)$ & $2(11.8)$ \\
\hline Follow-up oncological results (mo) & $23.0(17.0-29.3)$ & - \\
\hline Follow-up of questionnaires (mo) & - & $20.0(13.0-23.0)$ \\
\hline \multicolumn{3}{|l|}{ Stoma status at time of questionnaires } \\
\hline Never had a stoma & 4 & 4 \\
\hline Temporary stoma, already closed & 19 & 11 \\
\hline Stoma still present & 7 & 2 \\
\hline \multicolumn{3}{|l|}{ Tumor characteristic } \\
\hline Tumor heighta from anal verge $(\mathrm{cm})$ & $4.0(2.0)$ & $4.0(2.8)$ \\
\hline \multicolumn{3}{|l|}{$\begin{array}{l}\text { Height of the anastomosis from anal } \\
\text { verge }(\mathrm{cm})\end{array}$} \\
\hline $0-5.0$ & $24(80.0)$ & $13(76.5)$ \\
\hline $5.1-10.0$ & $6(20.0)$ & $4(23.5)$ \\
\hline \multicolumn{3}{|l|}{ Clinical TNM stage ${ }^{\mathrm{b}}$} \\
\hline $\mathrm{T} 1$ & $0(0)$ & $0(0)$ \\
\hline T2 & $11(36.7)$ & $7(41.2)$ \\
\hline T3 & $17(56.7)$ & $8(47.1)$ \\
\hline T4 & $2(6.7)$ & $2(11.8)$ \\
\hline NO & $18(60.0)$ & $11(64.7)$ \\
\hline N1 & $7(23.3)$ & $4(23.5)$ \\
\hline N2 & $4(13.3)$ & $1(5.9)$ \\
\hline N3 & $1(3.3)$ & $1(5.9)$ \\
\hline M0 & $24(80.0)$ & $13(76.5)$ \\
\hline Mx & $6(20.0)$ & $4(23.5)$ \\
\hline \multicolumn{3}{|l|}{ ypTNM stage, no metastasis } \\
\hline pTO & $3(10.3)$ & $2(11.8)$ \\
\hline pT1 & $5(17.2)$ & $2(11.8)$ \\
\hline pT2 & $11(37.9)$ & $6(35.3)$ \\
\hline pT3 & $10(34.5)$ & $7(41.2)$ \\
\hline NO & $22(75.9)$ & $11(64.7)$ \\
\hline N1 & $5(17.2)$ & $5(29.4)$ \\
\hline N2 & $2(6.9)$ & $1(5.9)$ \\
\hline
\end{tabular}

(Continued to the next)
Table 1. Continued

\begin{tabular}{lcc}
\hline Variable & $\begin{array}{c}\text { TaTME total } \\
\text { group } \\
(\mathrm{n}=30)\end{array}$ & $\begin{array}{c}\text { TaTME question- } \\
\text { naire completer } \\
(\mathrm{n}=17)\end{array}$ \\
\hline $\begin{array}{l}\text { Presence of pathologically assessed } \\
\text { EMVI }\end{array}$ & $2(6.7)$ & $1(5.9)$ \\
$\begin{array}{l}\text { Presence of pathologically assessed } \\
\text { lymph-invasion }\end{array}$ & $2(6.7)$ & $2(11.8)$ \\
$\begin{array}{l}\text { Additional therapy } \\
\text { Neoadjuvant }\end{array}$ & $14(46.7)$ & $9(52.9)$ \\
$\begin{array}{l}\text { Short course radiotherapy, } 5 \times 5 \text { Gy } \\
\text { Chemoradiation }\end{array}$ & $7(23.3)$ & $5(29.4)$ \\
Adjuvant chemotherapy & $7(23.3)$ & $4(23.5)$ \\
\hline
\end{tabular}

Values are presented as mean \pm standard deviation, number (\%), median (interquartile range), or number only.

TaTME, transanal total mesorectal excision; ASA, American Society of Anesthesiologists; PS, physical status; yp, postneoadjuvant pathologic stage; EMVI, extramural vascular invasion.

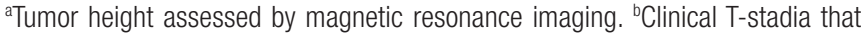
were reported as T1-2 were classified as T2. ' ${ }^{\circ}$ Chemoradiation consisted of $25 \times 2$ Gy radiotherapy and capecitabine of $825 \mathrm{mg} / \mathrm{m}^{2}$ twice a day.

scores was used for analysis, following the EORTC scoring manual [24]. Kaplan-Meier analysis was used to calculate LR-free cumulative survival at 24-months from the date of surgery. In this analysis, patients were censored when lost to follow up. No censoring for other oncological reasons (such as metastasis) took place. IBM SPSS Statistics ver. 25.0 (IBM Corp., Armonk, NY, USA) was used.

\section{RESULTS}

Between December 2016 and April 2019, 30 patients underwent TaTME for rectal cancer in Máxima Medical Centre, Veldhoven, the Netherlands and were eligible for evaluation. A total of 23 patients were eligible for questionnaire inclusion. The remaining 7 were excluded due to dementia $(\mathrm{n}=1)$, previously reported wish not to participate in studies $(n=3)$ or death $(n=3)$. Four patients returned blank questionnaires, 2 did not respond and 17 completed them all, leading to a response rate of $74 \%$. Table 1 provides all patient characteristics for the whole group and questionnaires completers separately. In the text below, the whole group $(n=30)$ is described. Most patients were male (80.0\%) with a median body mass index of $25.6 \mathrm{~kg} / \mathrm{m}^{2}\left(\mathrm{IQR}, 23.5-27.8 \mathrm{~kg} / \mathrm{m}^{2}\right)$. Most of the tumors were located in the first $5 \mathrm{~cm}$ from the anal verge (80.0\%) and almost half of the patients underwent neoadjuvant treatment (46.7\%). The median follow-up time for questionnaire completion was 20.0 months (IQR, 13.0-23.0 months). Three patients died during follow-up of which 1 was 2 days after surgery due to sepsis, 1 due to cerebral hemorrhage 2 months after surgery, and 1 cause remained unknown (progressive dementia and living in a nursing home). Bowel continuity at the time of study conduction 
was $76.7 \%$ (23 of 30) for the whole group and $88.2 \%$ (15 of 17) for questionnaire completers. Three patients received their stoma after their initial TaTME surgery ( 2 due to postoperative complications, 1 due to fecal incontinence).

\section{Fecal incontinence, bowel dysfunction, and its impact on quality of life}

Table 2 provides functional outcome scores. The median Wexner incontinence score was 9.0 (IQR, 7.0-12.0). All 15 non-stoma patients were symptomatic since respectively $6.7 \%, 33.3 \%$, and $60.0 \%$ of patients had mild, moderate, and severe incontinence. Analyzing individual patient records showed that 1 out of 3 patients was referred to a pelvic floor rehabilitation center. Median FIQL scores were respectively 3.7, 3.1, 3.3, and 3.7 for the domains of lifestyle, coping/behavior, depression/self-perception, and embarrassment. The median LARS score was 33.1 (IQR, 25.0-39.0) and $73.3 \%$ reported major LARS. One patient chose for the construction of a stoma due to complaints of fecal incontinence, while 5 others preferred transanal irrigation to improve their QoL (which it subjectively did according to notes in the patient files). Patients who used transanal irrigation reported that they scored their functional outcomes according to the situation prior to the start of irrigation.

Table 3 provides QoL data. Mean global health status was 82.8

Table 2. Overview of Wexner incontinence, LARS, and FIQL scores

\begin{tabular}{lc}
\hline Scale & TaTME group $(\mathrm{n}=15)$ \\
\hline Wexner incontinence score & $9.0(7.0-12.0)$ \\
Total score & \\
Degree of incontinence & $0(0)$ \\
Not symptomatic $(<1)$ & $1(6.7)$ \\
Mild (1-4) & $5(33.3)$ \\
Moderate (5-8) & $9(60.0)$ \\
Severe (>8) & \\
LARS score & $33.1(25.0-39.0)$ \\
Total score & \\
LARS category & $1(6.7)$ \\
No LARS & $3(20.0)$ \\
Minor LARS & $11(73.3)$ \\
Major LARS & \\
FIQL score & $3.7(3.4-4.0)$ \\
Lifestyle & $3.1(2.1-3.4)$ \\
Coping/behavior & $3.3(3.2-3.8)$ \\
Depression/self-perception & $3.7(3.0-4.0)$ \\
Embarrassment & $0 r(n+10)$ \\
\hline
\end{tabular}

Values are presented as median (interquartile range) or number (\%).

LARS, low anterior resection syndrome; FIQL, Fecal Incontinence Quality of Life; TaTME, transanal total mesorectal excision.
Table 3. Overview of EORTC QLQ C30 and CR29

\begin{tabular}{|c|c|}
\hline Category & Data \\
\hline \multicolumn{2}{|l|}{ QLQ C30 (n=17) } \\
\hline Global health status & $82.8 \pm 12.7$ \\
\hline Physical functioning & $92.2 \pm 10.1$ \\
\hline Role functioning & $86.3 \pm 17.9$ \\
\hline Emotional functioning & $88.7 \pm 15.6$ \\
\hline Cognitive functioning & $94.1 \pm 10.1$ \\
\hline Social functioning & $88.2 \pm 14.1$ \\
\hline Fatigue & $15.0 \pm 13.6$ \\
\hline Nausea and vomiting & $1.0 \pm 4.0$ \\
\hline Pain & $9.8 \pm 16.7$ \\
\hline Dyspnea & 0 \\
\hline Insomnia & $19.6 \pm 23.7$ \\
\hline Appetite loss & $1.9 \pm 8.1$ \\
\hline Constipation & $15.7 \pm 33.6$ \\
\hline Diarrhea & $9.8 \pm 15.7$ \\
\hline Financial difficulties & $3.9 \pm 11.1$ \\
\hline \multicolumn{2}{|l|}{ QLQ CR29 $(n=17)$} \\
\hline Body image & $10.5 \pm 12.1$ \\
\hline Anxiety & $17.6 \pm 17.1$ \\
\hline Weight loss & $19.6 \pm 29.0$ \\
\hline Urinary frequency & $27.5 \pm 26.9$ \\
\hline Blood and mucus in stool & $13.7 \pm 23.7$ \\
\hline Dysuria & $2.0 \pm 8.1$ \\
\hline Abdominal pain & $15.7 \pm 31.4$ \\
\hline Buttock pain & $11.8 \pm 20.2$ \\
\hline Bloating & $19.6 \pm 31.3$ \\
\hline Dry mouth & $35.3 \pm 83.7$ \\
\hline Hair loss & 0 \\
\hline Taste & $3.9 \pm 16.2$ \\
\hline Flatulence $^{\mathrm{a}}$ & $41.7 \pm 35.5$ \\
\hline Fecal incontinence $^{a}$ & $8.3 \pm 14.9$ \\
\hline Sore skin around anus ${ }^{\mathrm{a}}$ & $10.4 \pm 20.1$ \\
\hline Stool frequency ${ }^{a}$ & $20.8 \pm 17.7$ \\
\hline Embarrassment $^{\mathrm{a}}$ & $12.5 \pm 16.7$ \\
\hline Sexual interest, men $(n=12)$ & $36.1 \pm 22.3$ \\
\hline Impotence, men & $47.2 \pm 43.7$ \\
\hline Sexual interest, women $(n=5)$ & $40.0 \pm 43.5$ \\
\hline Dyspareunia, women $(n=4)$ & $16.7 \pm 33.3$ \\
\hline
\end{tabular}

Values are presented as mean \pm standard deviation.

EORTC, European Organization for Research and Treatment of Cancer; C30, core questionnaire; CR29, 29-item module.

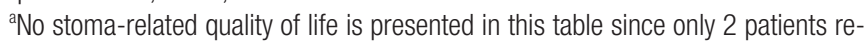
ported on this. 
Table 4. Surgical and oncological outcomes of all included 30 patients

\begin{tabular}{lc}
\hline Variable & Data \\
\hline Surgical outcome & \\
Construction of a temporary stoma at index surgery & \\
No, primary anastomosis & $7(23.3)$ \\
Yes, deviating or permanent stoma & $23(76.7)$ \\
Stoma closed at the present time & $20(66.7)$ \\
Time to stoma closure (mo) & $3.0(2.0-4.0)$ \\
Complications and morbidity & \\
Perioperative complications & 0 \\
Postoperative morbidity/mortality & $7(23.3)$ \\
Abscess (localized at rectum remnant) & $1(3.3)$ \\
Ileus & $2(6.7)$ \\
Anastomotic leakage & $3(10.0)$ \\
Number that had a protective stoma & $1(3.3)$ \\
Death due to sepsis & $1(3.3)$ \\
Type of anastomosis: & \\
End to end & $23(76.7)$ \\
Coloanal & $5(16.7)$ \\
Permanent colostomy (intersphincteric resection) & $2(6.7)$ \\
Number of 2-team procedures & $18(60.0)$ \\
Conversion rate & 0 (f yes: time till metastasis (mo) \\
Time of surgery (min) & $6(20.0)$ \\
Hospitalization (day) & \\
Oncological outcome & \\
Local recurrence & \\
\hline
\end{tabular}

Values are presented as number (\%) or median (interquartile range).

aThis resembles 1 patient that presented itself with both a local recurrence as with pulmonic, lymphatic, and peritoneal metastasis at 6-month follow-up.

(SD, 12.7) and all other functioning scales scored higher than 88.0 points. The colorectal-specific submodule showed scores of respectively $41.7,20.8$, and 12.5 for the symptom scales flatulence, stool frequency, and embarrassment. FIQL scored 8.3 points.

\section{Surgical and oncological outcomes in the first set of transanal total mesorectal excision patients}

Table 4 provides all surgical and oncological outcomes. In the first 30 patients that were treated in this hospital, no conversions were needed. The median time of surgery was 310 minutes and no nameable intraoperative complications occurred. In $23.3 \%$, no protective stoma was constructed next to an anastomosis at index sur-

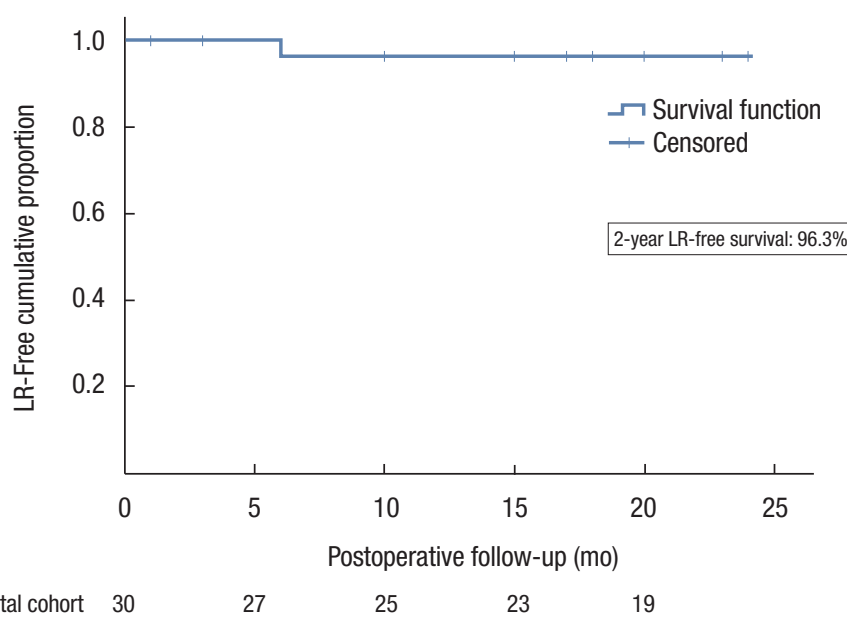

Fig. 1. The 2-year local recurrence (LR)-free proportion. LR, local recurrence.

gery. The majority (70.0\%) received a diverting ileostomy next to the construction of an anastomosis at index surgery, while the remaining 6.7\% received another stoma type, such as a colostomy. In 2 patients, a definitive colostomy was constructed. Serious postoperative complications such as abscesses, ileus, and AL occurred in respectively $3.3 \%, 6.7 \%$, and $10.0 \%$ of the cases, while 1 patient died due to postoperative sepsis with multiorgan failure due to an ischemic afferent colon based on poor microcirculation, not related to AL. Six patients underwent reoperations within 30 days (range, 2-7 days) after index surgery. Reasons were AL $(n=2)$, suspicion of $A L(n=1)$, second look due to sepsis with multiorgan failure $(\mathrm{n}=1)$, and nonfunctioning diverting stomata $(\mathrm{n}=2)$.

Regarding oncologic results, after a median follow-up of 23.0 months (IQR, 17.0-29.3 months), an LR was found in 2 patients. Patient 1 , initially postneoadjuvant pathologic stage (yp) T3N1M0 and MRF- (treated with neoadjuvant $5 \times 5$ Gy radiotherapy), presented itself with both a unifocal LR precoccygeal and extensive systemic disease at 6 months and received palliative chemotherapy. Patient 2, initially ypT3N1M0 and MRF+, showed a unifocal presacral LR at 27 months of follow-up and started with induction chemotherapy followed by chemoradiotherapy and surgery. No angioinvasion, extramural vascular invasion, or R1 resection at first surgery were reported for both. No multifocal recurrence pattern was seen. The 2-year actuarial cumulative LR rate, censored for patients lost to follow up, was 3.7\% (95\% CI, 2.4\%-5.0\%) (Fig. 1).

\section{DISCUSSION}

This institutional cohort study investigated the functional outcome and QoL of the first 30 patients that underwent TaTME for rectal cancer in a teaching hospital in the Netherlands and reported both surgical and oncologic outcomes. Functional complaints, in- 
cluding fecal incontinence, are common after TaTME but are compatible with good QoL if patients accept and support their treatment options. After a median follow-up of 23 months, oncological outcomes did not show any alarming results.

Since more patients outlive their cancer diagnosis, QoL and functional outcomes become more important. This study found a median LARS score of 33.1 and a prevalence of $73.3 \%$ major LARS. Previous studies reported major LARS percentages ranging from $21 \%$ to $84 \%[6,14,26-30]$ and median LARS scores that were lower (range, 10-36) than reported in the current cohort [6, 14, 26-30]. However, study populations did not covenant, especially since higher located tumors [6,27], shorter follow-up times [14, 28], and lower [27] or higher (this study reported $84.0 \%$ major LARS) [28] neoadjuvant treatment rates were reported compared with the present study. A study with similar patient characteristics showed similar results [30].

All patients showed some form of incontinence since no patient scored a Wexner incontinence score of zero. The median Wexner incontinence score was 9.0 which is in line with previously reported data $[15,28,31,32]$. These previous studies were comparable to our cohort regarding patient characteristics such as age, sex, and tumor height, although the follow-up time in 2 of them was shorter (3-6 months) [28, 32]. This suggests that no large improvements over time can be expected. In the study presented by Rubinkiewicz et al. [28], neoadjuvant treatment was more frequently used (up to $96 \%$ ), explaining a higher median Wexner incontinence score (11; range, 8-12). Regarding FIQL subdomains, scores did not differ from long-term data elsewhere [33] and didn't show clinically significant differences compared to a Dutch reference population [34]. Analyzing colorectal specific QoL showed that most domains that are associated with LARS were in line with previously reported data, namely flatulence (41.7; elsewhere range, 22.2-51.3), stool frequency (20.8; elsewhere, 19.8-36.4), and sore skin around the anus (10.4; elsewhere, 2.5-33.3). Surprisingly, the symptom scale domains fecal incontinence and embarrassment scored lower than previously reported, respectively 8.3 (elsewhere, 20.4-37.0) and 12.5 (elsewhere, 23.3-68.9) [6, 14, 15, 27, 35, 36]. Important to notice is that one patient choose to get a permanent colostomy as treatment of severe fecal incontinence, while 5 patients started with transanal irrigation to gain more control over their bowel movements. This is, in our opinion, a relatively high number and we suggest that an early, open, and patient-driven consultation on potential treatment options, as earlier described [37], could be contributory to this high number. This might also explain why LARS-specific QoL domains, such as fecal incontinence, are surprisingly good in relation to the relatively high median LARS and Wexner incontinence scores.

When discussing surgical outcomes and operation details, it is important to acknowledge that the surgeons were in their learning phase [38]. Although the AL and abscess rate (combined 13.3\%) was similar as described in the learning curve evaluation study of Koedam et al. [38], the overall major postoperative morbidity (20\% complications that required reintervention) was lower. Since the percentage of overall major postoperative morbidity can be used as a sensitive learning curve marker, it shows that our surgeons follow a steeper learning curve than the original pioneers in the field [38]. Other factors, such as the rate of construction of a primary anastomosis or time of hospitalization, showed no differences with previously reported studies, although the time of surgery was longer [38]. We emphasize the importance of a structured training pathway and proctoring program when adopting a new surgical technique, especially since TaTME can be challenging with regard to technical set-up, correct plane dissection, and purse-string placement [19].

The LR-free survival after TaTME was assessed as well. Within a median follow-up time of 23.0 months, 2 patients developed an LR. This represents a 2-year actuarial cumulative LR rate of 3.6\% (95\% CI, 2.4\%-5.0\%). It was the LR rates from previous studies, in the example of the Norwegians, that were alarming in the introduction phase of TaTME [7]. They reported short-term LR rates of $8 \%$ to $10 \%$ with an unconventional multifocal pattern and early occurrence, which is why the Norwegians stopped performing TaTME. However, recent multicenter data on 2- and 3-year LR rate ( $3.3 \%$ and $4.5 \%$, respectively; $\mathrm{n}=767$ ) from Roodbeen et al. [10] showed comparable results as with laparoscopic and open TME $[39,40]$. Although our results are derived from a small study population, no alarming results were found.

This study is limited by a small study population with relatively short to moderate follow-up time regarding oncological outcomes, although follow-up time is enough to report on postoperative function and QoL. Due to this small study population, some of the reported standard deviations, especially in the EORTC QoL list, are high. Also, this study reports the outcomes of the first 30 patients that underwent this challenging technique. Learning curve studies showed that postoperative outcomes improved after the first 40 patients [38], while it required up to 51 cases to reach an acceptable incidence of high-quality TME [41]. Therefore, it is expected that patients treated after these numbers may savor from improved surgical skills. This all underscores the importance of tertiary referral centers. As a final limitation, due to the study design, no baseline function before surgery was available.

Despite these limitations, this study provides insights into the consequences of TaTME surgery and supports the latest oncological data with acceptable LR rates after TaTME. As with every type of surgery, it is important to discuss all possible consequences (and potential treatment options) in an early phase. Embarrassment is common and patients often feel restrained in reporting functional complaints and their impact on daily life toward their surgeons. This emphasizes the importance of a postoperative care track that aims to define patient's personalized needs and evaluates the intrinsic motivation to choose for, for example, pelvic floor rehabilitation or transanal irrigation [37]. Since data about these treatment options after TaTME are lacking, we would like to stimulate others to investigate these effects and communicate them. 
In conclusion, TaTME may lead to significant functional impairments. Patients should receive preoperative counseling on this topic and be fully aware of the potential consequences of their treatment. Oncological data were in line with other short- to moderate-term data and did not show alarming results.

\section{REFERENCES}

1. Emile SH, de Lacy FB, Keller DS, Martin-Perez B, Alrawi S, Lacy $\mathrm{AM}$, et al. Evolution of transanal total mesorectal excision for rectal cancer: from top to bottom. World J Gastrointest Surg 2018; 10:28-39.

2. Chen TY, Emmertsen KJ, Laurberg S. Bowel dysfunction after rectal cancer treatment: a study comparing the specialist's versus patient's perspective. BMJ Open 2014;4:e003374.

3. Vironen JH, Kairaluoma M, Aalto AM, Kellokumpu IH. Impact of functional results on quality of life after rectal cancer surgery. Dis Colon Rectum 2006;49:568-78.

4. Dulskas A, Miliauskas P, Tikuisis R, Escalante R, Samalavicius $\mathrm{NE}$. The functional results of radical rectal cancer surgery: review of the literature. Acta Chir Belg 2016;116:1-10.

5. Sylla P, Rattner DW, Delgado S, Lacy AM. NOTES transanal rectal cancer resection using transanal endoscopic microsurgery and laparoscopic assistance. Surg Endosc 2010;24:1205-10.

6. Veltcamp Helbach M, Koedam TW, Knol JJ, Velthuis S, Bonjer $\mathrm{HJ}$, et al. Quality of life after rectal cancer surgery: differences between laparoscopic and transanal total mesorectal excision. Surg Endosc 2019;33:79-87.

7. Larsen SG, Pfeffer F, Kørner H; Norwegian Colorectal Cancer Group. Norwegian moratorium on transanal total mesorectal excision. Br J Surg 2019;106:1120-1.

8. Perdawood SK, Thinggaard BS, Bjoern MX. Effect of transanal total mesorectal excision for rectal cancer: comparison of shortterm outcomes with laparoscopic and open surgeries. Surg Endosc 2018;32:2312-21.

9. Suwanabol PA, Maykel JA. Transanal total mesorectal excision: a novel approach to rectal surgery. Clin Colon Rectal Surg 2017;30: 120-9.

10. Roodbeen SX, Spinelli A, Bemelman WA, Di Candido F, Cardepont M, Denost Q, et al. Local recurrence after transanal total mesorectal excision for rectal cancer: a multicenter cohort study. Ann Surg 2021;274:359-66.

11. Rasmussen OO, Petersen IK, Christiansen J. Anorectal function following low anterior resection. Colorectal Dis 2003;5:258-61.

12. Bruheim K, Guren MG, Skovlund E, Hjermstad MJ, Dahl O, Frykholm G, et al. Late side effects and quality of life after radiotherapy for rectal cancer. Int J Radiat Oncol Biol Phys 2010;76:1005-11.

13. Allaix ME, Rebecchi F, Giaccone C, Mistrangelo M, Morino M. Long-term functional results and quality of life after transanal endoscopic microsurgery. Br J Surg 2011;98:1635-43.

14. Koedam TW, van Ramshorst GH, Deijen CL, Elfrink AK, Meijerink WJ, Bonjer HJ, et al. Transanal total mesorectal excision (Ta-
TME) for rectal cancer: effects on patient-reported quality of life and functional outcome. Tech Coloproctol 2017;21:25-33.

15. van der Heijden JA, Koëter T, Smits LJ, Sietses C, Tuynman JB, Maaskant-Braat AJ, et al. Functional complaints and quality of life after transanal total mesorectal excision: a meta-analysis. $\mathrm{Br} \mathrm{J}$ Surg 2020;107:489-98.

16. Pucciani F. A review on functional results of sphincter-saving surgery for rectal cancer: the anterior resection syndrome. Updates Surg 2013;65:257-63.

17. Bloemen JG, Visschers RG, Truin W, Beets GL, Konsten JL. Longterm quality of life in patients with rectal cancer: association with severe postoperative complications and presence of a stoma. Dis Colon Rectum 2009;52:1251-8.

18. Peeters KC, Tollenaar RA, Marijnen CA, Klein Kranenbarg E, Steup WH, Wiggers T, et al. Risk factors for anastomotic failure after total mesorectal excision of rectal cancer. Br J Surg 2005;92: 211-6.

19. Veltcamp Helbach M, van Oostendorp SE, Koedam TW, Knol JJ, Stockmann HB, Oosterling SJ, et al. Structured training pathway and proctoring; multicenter results of the implementation of transanal total mesorectal excision (TaTME) in the Netherlands. Surg Endosc 2020;34:192-201.

20. Rahbari NN, Weitz J, Hohenberger W, Heald RJ, Moran B, Ulrich $\mathrm{A}$, et al. Definition and grading of anastomotic leakage following anterior resection of the rectum: a proposal by the International Study Group of Rectal Cancer. Surgery 2010;147:339-51.

21. van Heinsbergen M, Van der Heijden JA, Stassen LP, Melenhorst J, de Witte E, Belgers EH, et al. The low anterior resection syndrome in a reference population: prevalence and predictive factors in the Netherlands. Colorectal Dis 2020;22:46-52.

22. Deutekom M, Terra MP, Dobben AC, Dijkgraaf MG, Felt-Bersma RJ, Stoker J, et al. Selecting an outcome measure for evaluating treatment in fecal incontinence. Dis Colon Rectum 2005;48:2294301.

23. Rockwood TH, Church JM, Fleshman JW, Kane RL, Mavrantonis C, Thorson AG, et al. Fecal Incontinence Quality of Life Scale: quality of life instrument for patients with fecal incontinence. Dis Colon Rectum 2000;43:9-16.

24. Aaronson NK, Ahmedzai S, Bergman B, Bullinger M, Cull A, Duez NJ, et al. The European Organization for Research and Treatment of Cancer QLQ-C30: a quality-of-life instrument for use in international clinical trials in oncology. J Natl Cancer Inst 1993;85:36576.

25. Fayers PM, Aaronson NK, Bjordal K, Groenvold M, Curran D, Bottomley A; on behalf of the EORTC Quality of Life Group. The EORTC QLQ-C30 scoring manual. 3rd ed. Brussels: European Organisation for Research and Treatment of Cancer; 2001.

26. Dou R, Sun W, Luo S, Hou Y, Zhang C, Kang L. Comparison of postoperative bowel function between patients undergoing transanal and laparoscopic total mesorectal excision. Zhonghua Wei Chang Wai Ke Za Zhi 2019;22:246-54.

27. Bjoern MX, Nielsen S, Perdawood SK. Quality of life after surgery 
for rectal cancer: a comparison of functional outcomes after transanal and laparoscopic approaches. J Gastrointest Surg 2019;23: 1623-30.

28. Rubinkiewicz M, Zarzycki P, Czerwińska A, Wysocki M, Gajewska N, Torbicz G, et al. A quest for sphincter-saving surgery in ultralow rectal tumours-a single-centre cohort study. World J Surg Oncol 2018;16:218.

29. Reali C, Keller DS, Penna M, Hompes R. Low anterior resection syndrome: are we getting to the bottom of the problem with TaTME? Colorectal Dis 2018;20(Suppl 4):41.

30. Pontallier A, Denost Q, Van Geluwe B, Adam JP, Celerier B, Rullier E. Potential sexual function improvement by using transanal mesorectal approach for laparoscopic low rectal cancer excision. Surg Endosc 2016;30:4924-33.

31. Turrado-Rodriguez V, Torroella AT, De Lacy Oliver F, Guarner Piquet P, Otero-Pineiro A, Martin-Perez B, et al. Functional outcomes after tatme: retrospective analysis of quality of life and pelvic function. Dis Colon Rectum. 2018;61:e222.

32. de'Angelis N, Portigliotti L, Azoulay D, Brunetti F. Transanal total mesorectal excision for rectal cancer: a single center experience and systematic review of the literature. Langenbecks Arch Surg 2015;400:945-59.

33. Leão P, Santos C, Goulart A, Caetano AC, Sousa M, Hogemann G, et al. TaTME: analysis of the evacuatory outcomes and EUS anal sphincter. Minim Invasive Ther Allied Technol 2019;28:332-7.

34. 't Hoen LA, Utomo E, Schouten WR, Blok BF, Korfage IJ. The fecal incontinence quality of life scale (FIQL) and fecal incontinence severity index (FISI): validation of the Dutch versions. Neurourol Urodyn 2017;36:710-5.

35. Keller DS, Reali C, Spinelli A, Penna M, Di Candido F, Cunning- ham C, et al. Patient-reported functional and quality-of-life outcomes after transanal total mesorectal excision. Br J Surg 2019;106: 364-6.

36. Mora L, Zarate A, Serra-Aracil X, Pallisera A, Serra S, NavarroSoto S. Functional impairment and quality of life after rectal cancer surgery. Cir Cir 2018;86:140-7.

37. van der Heijden JA, van Heinsbergen M, Thomas G, Caers F, Slooter GD, Maaskant-Braat AJ. Implementation of a postoperative screening and treatment guidance for the low anterior resection syndrome: preliminary results. Dis Colon Rectum 2019;62:103342.

38. Koedam TW, Veltcamp Helbach M, van de Ven PM, Kruyt PM, van Heek NT, Bonjer HJ, et al. Transanal total mesorectal excision for rectal cancer: evaluation of the learning curve. Tech Coloproctol 2018;22:279-87.

39. Fleshman J, Branda ME, Sargent DJ, Boller AM, George VV, Abbas MA, et al. Disease-free survival and local recurrence for laparoscopic resection compared with open resection of stage II to III rectal cancer: follow-up results of the ACOSOG Z6051 randomized controlled trial. Ann Surg 2019;269:589-95.

40. Stevenson AR, Solomon MJ, Brown CS, Lumley JW, Hewett P, Clouston AD, et al. Disease-free survival and local recurrence after laparoscopic-assisted resection or open resection for rectal cancer: the australasian laparoscopic cancer of the rectum randomized clinical trial. Ann Surg 2019;269:596-602.

41. Lee L, Kelly J, Nassif GJ, deBeche-Adams TC, Albert MR, Monson JRT. Defining the learning curve for transanal total mesorectal excision for rectal adenocarcinoma. Surg Endosc 2020;34:153442. 